\title{
Is there a Good Moral Argument against Moral Realism?
}

\author{
Camil Golub ${ }^{1,2}$ iD
}

Accepted: 9 October 2020 / Published online: 13 October 2020

(C) The Author(s) 2020

\begin{abstract}
It has been argued that there is something morally objectionable about moral realism: for instance, according to realism, we are justified in believing that genocide is wrong only if a certain moral fact obtains, but it is objectionable to hold our moral commitments hostage to metaphysics in this way. In this paper, I argue that no version of this moral argument against realism is likely to succeed. More precisely, minimal realism-the kind of realism on which realist theses are understood as internal to moral discourse-is immune to this challenge, contrary to what some proponents of the moral argument have suggested, while robust non-naturalist realists might have good answers to all versions of the argument as well, at least if they adopt a certain stance on how to form metaphysical beliefs in the moral domain.
\end{abstract}

Keywords Moral realism $\cdot$ Moral arguments $\cdot$ Robust realism $\cdot$ Minimal realism

\section{Introduction}

Moral realism-the view that there are objective moral facts, to which we have reliable access-is often defended with moral arguments. Only realism, it is argued, can make good on commitments that we hold most dear, e.g. that genocide is wrong no matter what anyone thinks about it, while anti-realist views such as subjectivism or relativism have unpalatable consequences with respect to such first-order moral issues, so we have moral reason to accept realism. However, some philosophers have argued that there is something morally objectionable about realism itself. According to realism, for instance, we are justified in believing that genocide is wrong only if a certain moral fact obtains. So, if we discovered that there was no such fact, or that the moral facts were different, we would have to abandon our belief that

Camil Golub

camil.golub@rutgers.edu

1 Rutgers University-Newark, Newark, NJ, USA

2 University of Leeds, Leeds, UK 
genocide is wrong. But we should not hold our moral commitments hostage to metaphysics in this way. Or so the argument goes. ${ }^{1}$

A version of this worry was first raised by Blackburn (1993): those who insist that morality must have a metaphysical grounding, he argued, exhibit a defective sensibility, similar to the moral flaw involved in believing that nothing matters unless it matters to God. More recently, Erdur (2016), Hayward (2019), Bedke (2019) and Kremm (2019) have developed this argument in several directions, focusing on different connections that realists seem to posit between moral facts and our moral commitments. ${ }^{2}$ For instance, Erdur argues that the moral explanations offered by realists involve an independent moral reality in a problematic way, while Bedke and Kremm hold that realism is objectionable because it allows for revising our moral beliefs on purely non-moral, metaphysical grounds.

The different versions of this argument also vary with respect to their targets. Here we need to distinguish two versions of realism. Minimal realism is the kind of realism defended by Kramer (2009), Dworkin (2011), or Scanlon (2014), which interprets realist theses about moral truths and facts as internal to moral discourse, by relying on a deflationary account of these notions. On this view, for instance, the seemingly metaphysical claim that it is a fact that genocide is wrong is equivalent to the first-order moral claim that genocide is wrong. ${ }^{3}$ In contrast, robust non-naturalist realism holds that claims about moral facts and properties have genuine metaphysical content and are thus irreducible to mere moral verdicts. Erdur and Hayward take their arguments to undermine both of these versions of realism, ${ }^{4}$ while Bedke and Kremm target only robust realism, and Kremm suggests that his moral challenge to robust realism might even be a good reason to adopt minimal realism instead. ${ }^{5}$

In this paper, I will argue that no version of the moral argument against realism is likely to succeed. More precisely, minimal realism is indeed immune to this challenge, contrary to what Erdur and Hayward have suggested, while robust realists might have good answers to all versions of this argument as well, at least if they adopt a certain stance on how we should form metaphysical beliefs in the moral domain. I will end with some remarks on where this leaves the dispute between minimal and robust realism.

\footnotetext{
${ }^{1} \mathrm{I}$ focus on moral realism in this paper, following some proponents of this argument, but the discussion below can be extended to normative realism more broadly.

${ }^{2}$ Field (2009, p. 270) makes a similar point in passing: "I'm tempted to say that the moral realist has not only a dubious metaphysics, but also a dubious morality that allows torturing dogs under the condition that there are no straightforward moral facts, or under the condition that those moral facts permit or even require such torture."

${ }^{3}$ This version of realism is sometimes called relaxed or quietist realism, and some proponents of the view might reject the minimal label that I use here. Scanlon (2014), for instance, argues that his realism is not "minimalist," because it takes normative facts to be as robust as they can be, and gives normative statements "exactly the content and 'thickness' that they require when taken literally" (p. 28). However, I do not think that there is any substantive disagreement here: minimalism aims to capture precisely the ordinary meaning of terms like true and fact, and entails indeed that truths and facts understood in a minimalist way are as robust as they can intelligibly be. Another thing to note is that minimal realism might include the expressivist quasi-realism defended by Blackburn (1993) and Gibbard (2003), which also relies on a minimalist account of truth, fact, and other notions to make good on realist-sounding claims about normativity. Blackburn and Gibbard advertise their view as a sophisticated form of anti-realism, but a case might be made that there is no meaningful divide between quasirealism and minimal realism. I will not a take a stance on this issue here.

${ }^{4}$ See Erdur (2016), pp. 598-599, and Hayward (2019), pp. 909-910. I should note that Hayward actually doubts that minimal realism is a coherent view. What he argues is that, if this version of realism is coherent, then his moral challenge applies to it as well. I will also assume here that this view is coherent and a form of genuine realism.

${ }^{5}$ Naturalist realism has been largely ignored in this debate, so I will also set it aside. From here on, robust realism should be understood as referring to robust non-naturalist realism.
} 


\section{The Argument from Objectionable Counterfactuals}

Let me begin with what I take to be the least effective version of the moral challenge to realism, namely an argument from objectionable counterfactuals. The very proponents of this argument acknowledge that it runs into an important problem, but it is useful to see what this problem is and how it motivates more interesting challenges to realism.

According to this argument, realism is morally objectionable because it is committed to claims like the following: if the moral facts were different or inexistent, then genocide would not be wrong. Here is how Erdur (2016, p. 597) initially articulates her complaint against realism:

"What if genocide and slavery involved all the pain and suffering they involve, but there were no independent reality that dictated that they were wrong - would they then not be wrong? Is not the proper thing to say rather that genocide and slavery would be wrong even if there were no independent reality that dictated that they were wrong?"

Similarly, Hayward (2019) takes to realism to entail that, if there were no moral facts, then nothing would matter - a claim that he finds morally offensive. Erdur and Hayward take this argument to undermine both robust and minimal realism.

However, minimal realism is immune to this argument, because it treats seemingly metaphysical claims about moral facts as equivalent to first-order moral commitments, by relying on a minimalist account of facthood and other related notions. On this view, to say that it is a fact that genocide is wrong, or that there is an independent reality that makes it the case that genocide is wrong, amounts to nothing more than rehearsing the verdict that genocide is wrong. Therefore, the claim that "If there were no independent reality that dictated that genocide was wrong, then genocide would not be wrong" is equivalent to "If genocide was not wrong, it would not be wrong," which is trivially true, rather than a substantive claim that someone could challenge on moral grounds.

Robust realism might seem to be a better target for this argument. Realists such as ShaferLandau (2003) or Enoch (2011) hold that there are genuine metaphysical claims about, e.g., the existence of objective moral facts, which cannot be reduced to first-order moral claims. Therefore, such realists cannot trivialize the relevant counterfactuals in the way that minimal realists can: on their view, for instance, to suppose that there was no independent reality that made it the case that genocide was wrong is conceptually distinct from supposing that genocide was not wrong.

Robust realists can make a different case, however, that the counterfactuals involved in the moral argument are trivially true and therefore pose no threat to their view. Moral facts, or more precisely fundamental moral facts, are supposed to be metaphysically necessary. And if it is metaphysically impossible that the moral facts were different, then a claim such as "If there was no moral fact that made it the case that genocide was wrong, then genocide would not be wrong" would indeed be true, but so would a counterfactual with same antecedent and the opposite consequent, at least according to a standard semantics for counterfactuals with impossible antecedents. Such counterfactuals, therefore, cannot tell us much about the plausibility of robust realism.

If we focus on non-fundamental moral facts, on the other hand-i.e., facts that obtain in virtue of fundamental moral facts together with some relevant non-moral features of the world - then it is true that such facts could have been different, but only if the natural facts on which they supervene had been different as well. For example, if I had not made a promise 
to my friend yesterday, then there would have been no moral fact dictating that I must keep my promise to her, so I would not have had this moral duty. But there is nothing troubling about such counterfactuals: our moral commitments should be conditional on any relevant non-moral facts.

To sum up, robust realism typically does not allow that moral facts could have been different or inexistent while everything else about the world stayed the same, ${ }^{6}$ and this seems enough to make it immune to the argument from counterfactuals, as it can treat all relevant counterfactuals as either trivially true or benign.

Both Erdur and Hayward acknowledge the problem that the metaphysical necessity of moral facts poses for their arguments. In response, Erdur suggests that her moral challenge does not essentially rely on any claim about possible worlds, but rather concerns moral explanations. I turn to this version of the argument next. Hayward claims that we can morally evaluate people's attitudes towards metaphysically impossible scenarios, but he too primarily uses a different argument against realism, centered on epistemic possibility. I believe that this argument is indeed a more promising version of the moral challenge to realism, and will examine it in section $4 .^{7}$

\section{The Argument from Objectionable Explanations}

Erdur's argument from objectionable explanations against realism is modeled on similar arguments that are often made against anti-realist theories of morality. For instance, moral subjectivism seems to entail that slavery and genocide are wrong ultimately because we have certain negative attitudes towards them, which is arguably a moral misjudgment: slavery and genocide are wrong because of, say, all the suffering and loss that they involve, and not because we disapprove of them.

Similarly, Erdur argues, moral realism holds that what makes an action right or wrong is ultimately the fact that there is an independent reality that makes it right or wrong, and this claim should be rejected on moral grounds:

"[S] urely, the existence of an independently issued verdict-if there were such a verdict - that genocide is wrong would not be the main or ultimate reason why it is wrong. Genocide is wrong mainly and ultimately because of the pain and suffering and loss that it involves - regardless of whether or not the badness of such suffering and loss is confirmed by an independent reality." (Erdur 2016, pp. 597-598, her italics)

\footnotetext{
${ }^{6}$ I say "typically" to allow for the possibility of realists who reject supervenience.

${ }^{7}$ Someone might object that my dismissal of the argument from counterfactuals has been too quick: some counterfactuals with impossible antecedents are more plausible than others, it might be argued, and the right semantics for counterfactuals should accommodate this fact, rather than treating all such counterfactuals as trivially true. Moreover, as an anonymous reviewer points out, this objection is strengthened if we consider that a theist might similarly argue that we should not worry about making our moral commitments conditional on God's commands because it is metaphysically necessary that God exists and issues those commands, without intuitively addressing the moral complaint against the Divine Command Theory. I cannot properly engage with the question of counterfactuals with impossible antecedents here, but I believe we can reasonably set aside the argument from objectionable counterfactuals, given the availability of other versions of the moral argument against realism, which seem to capture the same intuitive complaint and leave the realist with no easy way to trivialize the issue.
} 
Once again, Erdur takes this argument to undermine not only robust realism, but also minimal realism: both views, she argues, are committed to the existence of independent or objective moral facts and take such facts to play a fundamental role in moral explanations.

However, minimal realists do not claim that moral explanations bottom out in general claims about the existence of objective facts, or even in specific objectivist commitments. And for good reason: for instance, neither "Genocide is wrong because there are objective moral facts," nor "Genocide is wrong because it is wrong no matter what anyone thinks about it" would be much of an explanation. Minimal realists do embrace moral objectivity, but as the result of substantive moral theorizing, rather than its starting point. ${ }^{8}$ When it comes to moral explanations, then, minimal realists can appeal to the same explanantia that Erdur favors. For instance, they can agree that it is ultimately the suffering and loss involved in genocide that make it wrong, rather than the existence of objective moral facts or the objective wrongness of genocide itself.

What about robust realism? Again, it might seem to be more vulnerable to Erdur's challenge. The core metaphysical tenets of robust realism are meant to be irreducible to ordinary moral commitments. Moreover, robust realists might indeed appeal to such metaphysical claims about moral facts and properties in order to offer deep explanations for moral truths. For example, we might expect a robust realist to endorse an explanation like the following: "Genocide is wrong" is true because there is an objective fact that makes it true. It is such metaphysical explanations that Erdur finds morally objectionable:

"Does it really make moral sense to take some peculiar metaphysical truth about the world (which is devoid of any moral content itself, as we have assumed) as the ultimate reason why we are justified in taking our judgments about genocide or slavery seriously, and standing our ground in such matters?" (Erdur 2016, p. 601)

In other words, her argument is that moral explanations should bottom out in morally relevant features of the world, and not in morally neutral metaphysical facts.

Robust realists can resist this argument in several ways. First, let us assume that such realists do propose metaphysical explanations of first-order moral truths, and these explanations involve moral facts or properties in a fundamental role. Now, why should we think of these moral entities as morally neutral or "devoid of any moral content," as Erdur characterizes them? The existence of an objective moral fact that makes it the case that genocide is wrong, it might be argued, is as morally significant as any feature of the world could be, and to assume that moral metaphysics is morally irrelevant is simply to beg the question against robust realism. ${ }^{9}$

Robust realists can also attempt to explain away the intuitions that drive Erdur's argument by distinguishing between moral and metaphysical explanations. Perhaps the existence of an objective moral fact is indeed the wrong kind of explanans to invoke in a first-order moral explanation of why genocide is wrong, which should appeal instead to such features of genocide as the suffering and loss that it causes. But once we go beyond first-order moral theorizing and look for a deeper explanation of morality, including for why certain moral

\footnotetext{
${ }^{8}$ As Dworkin (2011, p. 10) puts it: "The only intelligible case for the 'mind-independence' of some moral judgment is a moral argument showing that it would still be true even if no one thought it was."

9 Admittedly, someone might object that this response itself begs the question against Erdur's challenge, by taking for granted that non-natural facts are morally relevant. Cf. Dasgupta (2017), pp. 300-304, who argues that non-naturalists do not "play fair" if they build normative significance into the very definition of normative properties.
} 
explanations hold, the robust realist might argue, it is wholly appropriate to appeal to moral facts and properties in a fundamental explanatory role. ${ }^{10}$

These are some responses available to realists whose explanatory ambitions match Erdur's characterization of robust realism. But there is yet another way to resist Erdur's argument: robust realism need not purport to offer metaphysical explanations that go beyond first-order moral explanations, and which involve metaphysical facts in a fundamental role. Instead, robust realists might simply claim that moral explanations themselves are metaphysical explanations, without adding any problematic explanantia to them. For example, such realists could agree with Erdur that genocide is wrong ultimately in virtue of the suffering and loss that it involves, and not because there is some further metaphysical fact that makes it wrong. Their realism would be manifested, at least in part, in how they interpret such moral explanations, e.g. as capturing grounding relations that are part of the metaphysical structure of the world. ${ }^{11}$

In conclusion, robust realists can answer Erdur's explanatory challenge no matter how they construe the relation between moral and metaphysical explanations. Let me turn now to what I take to be the most promising versions of the moral argument against realism: an argument from epistemic possibility and a related argument centered on the methodological commitments of robust realism.

\section{The Argument from Epistemic Possibility}

Moral realism seems to entail that, if the moral facts turn out to be sufficiently different or inexistent, then our moral beliefs are wrong. Moreover, the antecedent of this conditional is an epistemic possibility that realists should take seriously, given that realism is standardly understood as allowing that we might be fundamentally wrong about what the moral facts are.

Some philosophers have argued that it is morally objectionable to hold our moral commitments hostage to beliefs about the moral facts in this way. Thus, Hayward (2019) holds that realism is morally offensive because it entails that, if there are no objective moral facts, then nothing matters, in the same way that, say, the Divine Command Theory of morality is objectionable because it makes our moral commitments hinge on God's existence. Similarly, Bedke (2019) argues that, insofar as realists are disposed to revise their beliefs on important moral issues upon discovering that the moral facts are different, this is an objectionable disposition to have.

Note that Hayward's target is realism itself and what it entails, while Bedke focuses on the psychology of those who accept realism. We should keep this in mind as we examine possible realist responses to this challenge. The arguments also focus on slightly different epistemic possibilities: discovering that there are no objective moral facts vs. discovering that the facts are different than we thought. However, I do not think much hinges on this, so I will just talk about the disjunctive possibility that the moral facts might be different or inexistent in what

\footnotetext{
${ }^{10}$ Blanchard (2019) offers precisely this response to Erdur: as he puts it, Erdur's explanatory argument relies on “an equivocation between the normative and metaethical 'why' and 'because'. As grounds for the wrongness of genocide, pain and suffering are not competitors with the dictate of an independent reality. Rather, the realist view is that the ultimate normative grounds for the wrongness of genocide are to be understood metaphysically as constituted by an independent reality." (p. 4) See also Horn (2020) and Enoch (forthcoming) for similar arguments.

${ }^{11}$ Note that a distinction can still be drawn between robust realism thus understood and minimal realism, insofar as the latter holds that moral explanations do not have substantive metaphysical content.
} 
follows. Finally, while Bedke's argument explicitly targets only robust non-naturalist realism, in virtue of its robust metaphysical commitments, Hayward holds that his argument extends to minimal realism as well.

Let me start, then, with minimal realism, which again can be easily shown to be immune to this challenge. For a minimal realist, there is no difference between supposing that we might be wrong in our beliefs about objective moral facts and supposing that our first-order moral beliefs might be wrong. For instance, discovering that there is no fact that makes it true that genocide is wrong is simply to discover that genocide is not wrong. If we do make this (very unlikely!) discovery, this should make us abandon the belief that genocide is wrong. This much should be uncontroversial: if it turns out that not- $p$, then we should not believe that $p$, at least in normal circumstances. This is not a substantive dependence claim to which someone can raise moral objections, but a matter of basic epistemic rationality.

At times, Hayward suggests that realism is objectionable simply because it allows that even our deepest moral commitments might in principle be mistaken, e.g. even while holding fixed all our other beliefs about the world, we might discover that we should not comfort a loved one who is in distress. But making sense of the possibility of fundamental error is usually seen as a desideratum for any view worth calling realism. Both minimal and robust realism do entail that we might in principle be correct about all the natural facts and yet be wrong in our moral beliefs, but this is just part of what it is to be a realist. If the argument from epistemic possibility reduces to complaining about this feature of realism, then it is not covering new terrain, but is merely the expression of a fundamental disagreement between realists and antirealists. In any case, this issue has little to do with any objectionable dependence relation between our beliefs and some separate domain of facts, at least when it comes to minimal realism. $^{12}$

Once again, robust realism might seem to be at greater risk in the face of this argument from epistemic possibility. Robust realism seems to be committed to there being some "extra metaphysics beyond the natural ways of the world" (Bedke 2019, p. 2) on which our moral commitments are conditional, such that discovering that this independent metaphysical reality was different or inexistent could undermine said commitments. But such metaphysical discoveries should make no difference to our first-order moral beliefs. Or so the argument goes.

It is important to note what this argument does not say. Hayward and Bedke do not claim that all non-moral discoveries are irrelevant to our moral commitments. Some non-moral factual questions, e.g. whether a fetus can feel pain, can clearly be relevant to our moral beliefs. Moreover, even our fundamental moral commitments might hinge on non-moral facts, including metaphysical facts: learning that there is no external world might be enough to conclude that no action is morally wrong, not even genocide. But there are also bad cases where certain non-moral facts should not influence our moral beliefs: for instance, learning that a prospective tenant is gay is irrelevant to whether one ought to lend an apartment to that person. The argument from epistemic possibility claims that the metaphysical discovery that the moral facts are different or inexistent belongs with the bad cases: it is the kind of non-moral evidence that should not influence our moral commitments, contrary to what realism entails.

\footnotetext{
12 This is not to say that allowing for the possibility of fundamental moral error poses no problem for realism. Even some self-described realists, e.g. Nagel (1986), reject the idea that moral truths could radically outstrip our capacity to discover them. But whatever problem realists might face here, it is different, I take it, from the complaint that realism holds our moral commitments hostage to metaphysics.
} 
First, let me discuss some responses that realists have offered to this challenge which I do not find successful.

FitzPatrick (2018) has responded to an early version of this challenge by denying that being a realist entails being disposed to revise one's moral commitments upon making certain metaphysical discoveries. If a realist came to believe that there are no non-natural moral facts, FitzPatrick argues, he could still hold on to his moral commitments, and abandon instead the belief that such moral commitments need a metaphysical foundation in non-natural facts. For instance, such a person might try to vindicate the apparent objectivity and categorical force of his moral beliefs by becoming a naturalist realist instead, or perhaps by adopting a sophisticated version of anti-realism that allows for some measure of moral objectivity. ${ }^{13}$

This response, however, is not much of a defense of realism. What it offers is the prospect that one will abandon realism in certain circumstances in order to preserve one's moral probity. At best, this might be a good response to Bedke's version of the challenge, which targets the realists' psychology, but it does little to address Hayward's complaint that realism itself has morally objectionable consequences. Indeed, FitzPatrick's move seems to support Hayward's argument, by conceding that, if we were to make certain metaphysical discoveries, we would have to choose between accepting realism and preserving our moral commitments.

Moreover, FitzPatrick's response might not even work as a defense of the realists' psychological dispositions: while realists might be willing to jump ship and adopt other metaethical views upon making certain metaphysical discoveries, their current acceptance of realism can still be challenged on moral grounds, insofar as realism has morally objectionable consequences of which they are aware. ${ }^{14}$

Perhaps, though, realists have a different option here: they might deny that realism entails that we should abandon our moral beliefs upon making certain metaphysical discoveries. This is the line taken by Blanchard (2019):

"[I]t would be objectionable that someone would commit themselves to abandoning first-order moral commitments conditional on coming to believe that realism is false, but such a commitment is not constitutive of being a realist.” (p. 6)

According to Blanchard, while realists appeal to the existence of objective facts in order to make sense of their moral commitments, and this might lead them to hold that, if realism turns out to be false, then they should abandon those moral commitments, the latter claim is not entailed by realism; it is simply what some realists happen to believe. ${ }^{15}$

However, I do not see how the claim that the justification of our moral commitments depends on the existence of objective moral facts can be separated from realism itself. Realism, I take it, is not only a set of metaphysical claims about the existence of moral

\footnotetext{
${ }^{13}$ Enoch (forthcoming) offers a similar response to Bedke and Hayward. Even if realists accept conditionals such as "If there are no non-natural properties, then no action is wrong," he argues, they need not be committed to using such conditionals in modus-ponens inferences upon coming to believe their antecedents; in such circumstances, they can cease to accept these conditionals.

${ }^{14} \mathrm{Cf}$. Field (2009): "I don't believe the point is adequately answered by noting that an erstwhile realist who discovered there to be no straightforward normative facts would almost certainly continue with those moral preferences, and give up her view that she must base moral preferences on beliefs about such facts. For it's still the case that while she's a realist she has those conditional preferences; and those conditional preferences strike me as morally objectionable." (fn. 23, p. 270)

${ }^{15}$ In making this argument, Blanchard focuses on the commitment to stand one's ground in moral disagreements, but I take it that his argument is meant to concern the resilience of our moral commitments more generally, whether or not this resilience is manifested in the context of moral disagreements.
} 
facts or properties, but also includes certain bridge principles connecting such metaphysical claims with first-order moral claims: e.g., if there is no objective fact that makes it the case that genocide is wrong, then genocide is not wrong. Indeed, the metaphysical theses of realism are typically defended by appealing to the objectionable moral consequences of supposing that there are no objective moral facts. So realism does seem to entail that, if the metaphysical facts turn out to be different, then our current moral beliefs are false, e.g. genocide is not wrong.

Now, it is true that the question of whether genocide is wrong is, strictly speaking, distinct from the question of whether we should believe that genocide is wrong, or from the question of when it would be appropriate to abandon this belief. Perhaps there are practical reasons to continue believing that genocide is wrong even upon discovering that genocide is not wrong. But even so, realism does entail that, if there is no objective fact that makes it the case that genocide is wrong, then genocide is not wrong, and therefore, as a matter of basic epistemic rationality, we should not believe that genocide is wrong. This is all that the argument from epistemic possibility needs to get off the ground. ${ }^{16}$

Here is how I believe robust realists should respond to this argument from epistemic possibility: by arguing that the only kind of evidence that could support believing that the moral facts are different, and thus lead us to revise our moral commitments, is the same type of evidence that would support revising our moral beliefs in the first place. Aside from first-order moral evidence, this might include higher-order evidence about one's moral beliefs, or considerations about the simplicity and explanatory power of one's moral views. If realists were to adopt this methodological stance on the right way to form metaphysical beliefs about moral facts, they could hold that it is not epistemically possible for the moral facts to substantially diverge from our moral commitments, at least if our beliefs are formed through the right kind of process. Any situation in which it would be epistemically rational to believe that the moral facts are different or inexistent would be a case where we are already justified to some extent in revising our moral beliefs accordingly.

Now, it is not obvious that robust realists can adopt this methodological stance. Indeed, another version of the moral argument focuses precisely on the question of what kind of evidence robust realism treats as relevant for our moral commitments: realism, the argument goes, objectionably entails that we could settle first-order moral questions based on purely metaphysical evidence. Therefore, whether or not the response I suggested above succeeds depends on whether realists can address this deeper methodological challenge, which is the focus of the next section.

\footnotetext{
${ }^{16}$ Jessica Isserow has suggested to me in personal communication that realists might be able to dodge the argument from epistemic possibility by adopting the view that fundamental moral truths are conceptual truths, knowable a priori. See, e.g., Cuneo and Shafer-Landau (2014). On this view, she says, there would be "some kind of a priori insurance against discovering that at least a certain class of our moral commitments are radically false". However, I do not think this is a promising response to the challenge, not only because I find the view independently implausible (for reasons I will not discuss here), but also because I do not think it would really get realists off the hook in the face of the argument from epistemic possibility. As long as realists allow-as they should! - that we might be wrong about what the relevant conceptual truths are, this will be enough to get a new version of the argument from epistemic possibility off the ground, centered on conditionals such as: "If it turns out that 'Pain is bad' is not a conceptual moral truth, then..."
} 


\section{The Methodological Argument}

Bedke (2019) and Kremm (2019) argue that robust realism faces a moral problem due to its methodological commitments: given that such realists treat metaphysical claims about moral facts as irreducible to first-order moral claims, they must allow that there is some purely nonmoral evidence or way of reasoning that would support believing that the moral facts are different or inexistent, and thus make it rational to revise or abandon our moral beliefs. But holding our moral commitments hostage to purely non-moral, metaphysical evidence is an objectionable way of forming moral beliefs. Or so the argument goes.

This argument cuts deeper than the argument from epistemic possibility: it does not just claim that we should not hold our moral beliefs hostage to metaphysical beliefs about the moral facts. It purports to explain why we should not do so, namely because metaphysical beliefs can be rationally supported by types of evidence that would be improper evidence for moral beliefs.

What kind of evidence could this be? Bedke offers a far-fetched example: if realism were true, he argues, then we could in principle learn from an oracle that the instantiation of moral properties in the world is different than we had taken it to be, which should then lead us to revise our moral commitments accordingly, on pain of irrationality. ${ }^{17}$

I do not find this example particularly effective, because it relies on pure testimony as a possible source of evidence for metaphysical beliefs. There is a lively debate in metaethics about whether we could ever form justified moral beliefs or gain moral knowledge by pure testimony, and it might be argued that similar issues arise for metaphysical beliefs about morality: perhaps Bedke's oracle is not just actually unavailable as a source of evidence for metaphysical beliefs about moral facts, but nothing like it could in principle provide such evidence.

Now, I have only expressed some suspicions about Bedke's example and pure testimony in metaphysics, not an actual argument. Moreover, the issue of pure testimony might seem to be a red herring here. Bedke's more general point is that robust realism, by its nature, must allow for certain kinds of non-moral evidence for metaphysical beliefs, which would be improper evidence for moral beliefs, and this argument can still stand even if we dismiss pure testimony as a source of evidence for metaphysical beliefs.

Kremm offers more plausible examples of what the relevant problematic evidence might be, namely theoretical considerations that seem to be specific to metaphysical inquiry: e.g., considerations regarding ontological parsimony, how moral facts fit into our broader metaphysical picture of the world, or epistemological considerations about our access to moral facts. ${ }^{18}$ We cannot legitimately revise our moral beliefs on the basis of such evidence, he argues.

In responding to this methodological argument, let me start with the obvious: minimal realism is entirely immune to this challenge. On this view, metaphysical beliefs about moral facts etc. are first-order moral beliefs, so it is trivially the case that evidence about what the moral facts are is evidence for our moral beliefs. And to be clear, neither Bedke nor Kremm claims that minimal realism has anything to worry about here. Indeed, Kremm suggests that

\footnotetext{
${ }^{17}$ Hayward (2019, p. 910) uses a similar example in passing, and so does Donelson (2017) in his argument that metaethics should be irrelevant in moral deliberation.

${ }^{18}$ Hayward (2019, p. 906) similarly argues that considerations of parsimony and explanatory power should be irrelevant to our moral beliefs.
} 
this methodological challenge to robust realism might be a good argument for minimal realism.

What about robust realism? Here is the thought that I want to explore, which I already suggested as a response to the argument from epistemic possibility: robust realists might claim that, even though metaphysical beliefs about moral facts are conceptually distinct from firstorder moral beliefs, they are supported by the same kind of evidence, and moreover, cannot be supported by different types of evidence. To be sure, I am not saying that all or most actual robust realists would endorse such a claim. But this response to the methodological challenge would be consistent, I believe, with the core theses of robust realism: (1) there are objective normative facts, to which we have reliable access; and (2) all realist talk of normative facts, properties, etc. should be understood in a robust metaphysical sense.

The idea that there need be no methodological gap between our moral and metaphysical beliefs might seem to go against the very definition of robust realism. If robust realists treat metaphysical beliefs about moral facts as irreducible to mere moral beliefs, must they not allow for the existence of information that is epistemically relevant for our metaphysical commitments and thereby for our moral commitments, but which is also not the kind of information relevant in ordinary moral reasoning?

I do not think so. While accepting such a methodological gap between moral and metaphysical beliefs is certainly compatible with robust realism, I do not see why it should be treated as an intrinsic feature of the view.

Here is a broad picture of the relation between moral beliefs and metaphysical beliefs about the moral domain that I believe robust realists can endorse. We have all sorts of evidence for our moral beliefs: not only straightforwardly moral evidence, but also higher-order evidence about our moral beliefs, epistemological considerations, evidence about how these beliefs fit with our other beliefs about the world, or considerations about the simplicity and explanatory power of our moral views. (Think about disputes in fundamental moral theory, where such theoretical virtues often play a role. ${ }^{19}$ In addition to ordinary moral beliefs, we also form beliefs about the moral facts and properties underlying our moral commitments. We need to treat these other beliefs as having genuine metaphysical weight, and not just as mere moral beliefs in disguise, in order to be justified in treating our moral commitments as objective and categorical. $^{20}$ But this does not mean that said metaphysical beliefs are about a different domain of facts than moral beliefs: they are, after all, beliefs about moral facts, properties, etc. Nor does it mean that these metaphysical beliefs could be supported by a different kind of evidence than moral beliefs: they are, and can only be, supported by first-order moral evidence, epistemological considerations and higher-order evidence about our beliefs, evidence about

\footnotetext{
${ }^{19}$ As I mentioned in fn. 19, Hayward argues that one problem with realism is that it treats considerations about parsimony and explanatory power as relevant to moral questions: "I think our norms of moral evidence legislate that these considerations could not in principle be relevant to the question of whether I ought to comfort my ailing partner, or whether anything matters" (2019, p. 906). However, this complaint relies on an overly narrow construal of moral inquiry and morally relevant evidence. Theoretical considerations about simplicity and explanatory power might not be salient in ordinary moral contexts, and might not be sufficient on their own to overturn the moral commitments that we hold most dear. But such considerations can play a role in fundamental moral theory, e.g. in a dispute between Kantian deontologists and Ross-style pluralists.

${ }^{20}$ An anonymous reviewer notes that this idea that claims about moral facts and properties have genuine metaphysical weight is not entirely clear. I agree, and more generally I believe it is not easy to articulate a stable divide between robust and minimal realism, given that minimal realists do not reject metaphysical talk, but rather reintepret it as internal to moral discourse. But I am assuming that we can make sense of this divide, at least for the purposes of this paper. More on the dispute between minimal and robust realism, in the concluding section.
} 
how our beliefs fit with our scientific understanding of the world or about the simplicity and explanatory power of our beliefs, where all such evidence concerns both our moral beliefs and our metaphysical beliefs about the moral domain. In other words, moral metaphysics is a natural extension of moral theory, which does not involve any significantly different methodology.

By adopting this picture of the moral domain, I believe robust realists can successfully address the methodological argument. Take the belief that it is an objective fact that we ought to keep our promises, understood as having robust metaphysical content, and the first-order belief that we ought to keep our promises. The types of evidence relevant for the two beliefs are the same, the realist can argue, and they include both straightforwardly moral evidence and more theoretical considerations which are typically associated with metaphysical inquiry. This is not to say that the specific evidence relevant to each belief will necessarily be the same: for instance, parsimony considerations might weigh more in a metaphysical context than in a purely moral one. However, what matters is that robust realism thus understood will not entail that we could end up revising or abandoning our moral beliefs on the basis of improper evidence. The only kind of evidence that could ever lead us to think that the moral facts are different than we had thought, the realist can say, is the same type of evidence that we routinely use in moral inquiry, extended to metaphysical questions. ${ }^{21}$ All of this, again, seems to be compatible with the core theses of robust realism, particularly with the distinction between first-order moral claims and metaphysical claims about morality.

This response to the methodological argument and to the previous argument from epistemic possibility might strike some readers as ad hoc: perhaps this is the thesis that realists need in the face of these moral challenges, and maybe it is even compatible in principle with the core ideas of robust realism, but is this methodological picture independently defensible? Why should we think that there can be no evidence for realism, understood as a genuinely metaphysical view, other than the kinds of evidence that we use in moral theory? For instance, should we not expect robust realists to be concerned with such matters as the supervenience of moral properties on natural properties or our epistemic access to moral truths, which seem irrelevant for moral theory?

My response here is in two steps. First, questions about supervenience or moral epistemology can be seen as internal to, or intimately tied with, moral theory or normative theory more generally. The best evidence for this comes from the very existence of minimal realism, which deals with such matters despite reducing realism to a position within first-order moral theory: from a deflationary standpoint, talk of moral facts and properties is not eliminated but rather reinterpreted as an organic part of moral theory, and the same applies to the philosophical problems connected with these metaphysical notions, such as issues about supervenience or epistemic access. Of course, robust realists are not minimal realists: they reject deflationism about metaphysical matters and the corresponding internal interpretation of metaethical questions. But this does not mean that they must treat metaethical questions as somehow isolated from moral theory, or as responsive to a radically different kind of evidence-to be settled in the ontology room, as it were. Their disagreement with minimal realists

\footnotetext{
${ }^{21}$ FitzPatrick (2018) might have a similar idea in mind when he says that realism does not entail that "it should be possible to settle first-order moral questions - perhaps in surprising ways - through some sort of direct metaphysical discovery (independent of ethical methodologies) of certain non-natural properties in the world." (p. 549)
} 
fundamentally concerns how to interpret the core commitments of realism and is grounded in a metametaphysical dispute about the nature of truth, facts, etc., but this disagreement need not lead to any significant difference between how the two parties arrive at their realist commitments.

Secondly, I acknowledge that not all robust realists will be happy to adopt the methodological stance sketched above. Some of them might insist that metaphysical claims about morality are not only distinct from first-order moral claims, but cannot be settled using only the tools of moral theory, and they might complain that my defense of robust realism in this paper amounts in effect to watering down its metaphysical and methodological commitments to the point where it becomes overly similar to minimal realism. ${ }^{22}$ Perhaps such realists too can successfully address Bedke's and Kremm's methodological challenge, but I for one am not sure how. In any case, my goal here has been to articulate one way of responding to the methodological argument against realism, which aligns with what I take to be an independently plausible version of robust realism: a view that treats its metaphysical commitments as intimately tied with moral inquiry and responding to the same kinds of evidence.

\section{In Lieu of a Conclusion}

The dispute between minimal and robust realism is one of the most intractable in contemporary metaethics: the two theories seem to agree in their central commitments, but disagree about how to interpret those commitments. Perhaps due to its very nature as a dispute about how to understand realism itself, this debate has been marked by dialectical stalemates.

When I started thinking about this paper, I hoped that the moral argument against realism might be a way to make progress in this debate: it might show that robust realism faces a deep problem to which minimal realism is immune. Needless to say, I do not think that anymore. I have argued above that both minimal and robust realists have good answers to all versions of the moral argument, at least if robust realism is understood as ruling out a methodological gap between moral and metaphysical inquiry.

If anything, the divide between minimal and robust realism becomes even more elusive than it already was, if the two sides agree not only on the existence of objective moral facts and our reliable access to such facts, but also on what kind of evidence can support or undermine realist commitments, and only disagree about whether those realist commitments have genuine metaphysical weight. The debate seems to reduce to a metametaphysical dispute about the nature of truth and facthood, or perhaps about the metasemantics of moral discourse - say, about the explanatory role of truth and reference relations in the theory of meaning - without any significant upshot for how metaethical theorizing should be carried out or for the connection between metaethics and first-order moral theory.

But perhaps this is all as it should be. Just as two people can agree in their scientific realism even if one is a deflationist about truth and the other is a correspondence theorist, it might be time for minimal and robust realists to worry less about what divides them, treat each other as realists in any sense that matters, and focus on their common goals and challenges. I hope to have shown that the moral argument against realism need not be one of these challenges.

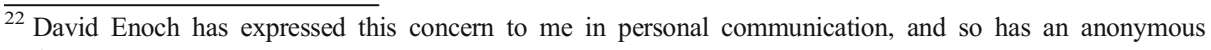
reviewer. 
Acknowledgements I am grateful to Daniel Elstein, Jessica Isserow, Gerald Lang, Jordan MacKenzie, Teemu Toppinen, Pekka Väyrynen, Robbie Williams, Mike Zhao, two anonymous reviewers for this journal, and audiences at the University of Leeds and the University of Helsinki for helpful comments and discussion on earlier versions of the paper. Many thanks also to Sean Aas, Rob MacDougall, Wouter Kalf, Colin O'Neill, Jacob Sparks, Bart Streumer, Travis Timmerman, Ralph Wedgwood, and an audience at the University of Groningen for their useful feedback on an ancestor of this paper in which I was arguing that there is a good moral argument against robust realism. Part of the research for this paper was funded through the European Union's Horizon 2020 research and innovation program under the Marie Skłodowska-Curie grant agreement No 837036.

Open Access This article is licensed under a Creative Commons Attribution 4.0 International License, which permits use, sharing, adaptation, distribution and reproduction in any medium or format, as long as you give appropriate credit to the original author(s) and the source, provide a link to the Creative Commons licence, and indicate if changes were made. The images or other third party material in this article are included in the article's Creative Commons licence, unless indicated otherwise in a credit line to the material. If material is not included in the article's Creative Commons licence and your intended use is not permitted by statutory regulation or exceeds the permitted use, you will need to obtain permission directly from the copyright holder. To view a copy of this licence, visit http://creativecommons.org/licenses/by/4.0/.

\section{References}

Bedke MS (2019) A dilemma for non-naturalists: irrationality or immorality?. Philos Stud 1-16

Blackburn S (1993) Essays in quasi-realism. Oxford University Press

Blanchard J (2019) Melis Erdur's moral argument against moral realism. Ethical Theory Moral Pract 22:371-377

Cuneo T, Shafer-Landau R (2014) The moral fixed points: new directions for moral nonnaturalism. Philos Stud 171:399-443

Dasgupta S (2017) Normative non-naturalism and the problem of authority. Proc Aristot Soc 117:297-319

Donelson R (2017) Ethical pragmatism. Metaphilosophy 48:383-403

Dworkin R (2011) Justice for hedgehogs. Belknap Press of Harvard University Press

Enoch D (2011) Taking morality seriously: a defense of robust realism. Oxford University PressEnoch D (forthcoming) Thanks, we're good: why moral realism is not morally objectionable. Philos Stud

Erdur M (2016) A moral argument against moral realism. Ethical Theory Moral Pract 19:591-602

Field H (2009) Epistemology without metaphysics. Philos Stud 143:249-290

FitzPatrick WJ (2018) Representing ethical reality: a guide for worldly non-naturalists. Can J Philos 48(3-4): $548-568$

Gibbard A (2003) Thinking how to live. Harvard University Press

Hayward MK (2019) Immoral realism. Philos Stud 176:897-914

Horn J (2020) On moral objections to moral realism. J Value Inquiry 54:345-354

Kramer MH (2009) Moral realism as a moral doctrine. Wiley-Blackwell

Kremm D (2019) How to be a metaethical quietist. Unpublished manuscript

Nagel T (1986) The view from nowhere. Oxford University Press

Scanlon TM (2014) Being realistic about reasons. Oxford University Press

Shafer-Landau R (2003) Moral realism: a defence. Oxford University Press

Publisher's Note Springer Nature remains neutral with regard to jurisdictional claims in published maps and institutional affiliations. 